\title{
Sergio González Miranda, Cristian Ovando Santana, Ingrid Bretón Winkler (editores). 2016. Del Hito a la Apacheta. Bolivia-Chile: otra lectura de cien años de historia transfronteriza (1904-2004). Santiago de Chile: RIL Editores.
}

\author{
Ingrid Bretón Winkler* \\ Estudiante de Magíster en Estudios Internacionales \\ del Instituto de Estudios Avanzados, Universidad de Santiago de Chile.
}

El libro se construye en el marco del Proyecto Anillo SOC 1109 (financiado por CONICYT), llevado a cabo por el Instituto de Estudios Internacionales de la Universidad Arturo Prat y el Instituto de Estudios Avanzados de la Universidad de Santiago de Chile. Del Hito a la Apacheta, editado por Sergio González, Cristian Ovando e Ingrid Bretón, tiene por objetivo desentrañar los distintos sentidos de los vínculos emprendidos por cien años entre chilenos y bolivianos desde distintas dimensiones: la regional transfronteriza, la interestatal y los aspectos culturales, religiosos, sociales e ideológicos. Resulta de investigaciones y reflexiones que han rescatado más la paradiplomacia que la diplomacia; las escalas locales, regionales y transfronterizas que la nacional; el enfoque heterológico por sobre la mirada centralista y estatal; una compresión del desarrollo desde abajo hacia arriba y no desde arriba hacia abajo; y a los actores sociales sub-nacionales y subregionales por sobre los actores nacionales e internacionales. En suma, intenta salir del encuadre de la historia diplomática más tradicional, que abunda en los estudios sobre las complejas relaciones vecinales que han emprendido las sociedades chilenas y bolivianas desde el Tratado de Paz y Amistad de 1904.

Para la generación de este libro se consideraron los aportes de reconocidos especialistas chilenos en diversas aproximaciones desde las ciencias sociales que han profundizado en las relaciones chileno-bolivianas. Es el caso de los doctores Sergio González (premio nacional de historia 2014), José Antonio González, Orietta Ojeda, Luis Castro, Cristian Garay, Isaac Caro, Gilberto Aranda y Loreto Correa, entre otros. Se compone de cuatro secciones que agrupan artículos de acuerdo a diferentes temáticas. También cabe destacar el esfuerzo de los editores por contemplar la participación de jóvenes investigadores/as que actualmente se encuentran cursando programas de doctorado y magíster. Esta iniciativa cumple así uno

Socióloga. Universidad de la Frontera. Estudiante de Magíster en Estudios Internacionales, Instituto de Estudios Avanzados, Universidad de Santiago de Chile. Correo electrónico: breton.winkler.ingrid@gmail.com 
de los objetivos relevantes que se proponen ambos institutos y sus proyectos: incentivar a los jóvenes investigadores en formación académica a generar conocimiento.

Del Hito a la Apacheta se estructura en cuatro secciones, cada una de las cuales se agrupa en artículos que se vinculan en temáticas propias de las relaciones internacionales a escala paradiplomática y/o transfronteriza emprendida por Bolivia y Chile, logrando así generar una interesante discusión desde diferentes lentes y actores para dimensionar las interacciones sociales, políticas, culturales, educacionales y económicas que se han generado a lo largo de la compleja historia que comparten estas sociedades y que ha estado colmada por el campo semántico estatal, dejando en la penumbra el acontecer internacional llevado a cabo por otros actores.

La sección 1 se titula "Religión e ideología en las relaciones entre Bolivia y Chile" y agrupa los artículos: "Movimientos religiosos en Chile y Bolivia: los casos del Islam y del judaísmo", por el Dr. Isaac Caro; el artículo "El mito en el pensamiento boliviano y su influjo en las RR.II.", por José Orellana; y "Caminos de ida y vuelta: el anarquismo e internacionalismo proletario en América del Sur. Chile y Bolivia en las primeras décadas del S.XX.", por Ivanna Margarucci y Eduardo Godoy. Esta sección, en su conjunto, nos introduce en la circulación de las ideas como resultado de procesos migratorios y otras formas de movilidad. El judaísmo, el islam, la identidad boliviana (respecto al Océano Pacífico en tanto reivindicación), el anarquismo y el internacionalismo como símbolos de los asentamientos, así como los movimientos y las generaciones de redes socio-culturales entre estas comunidades de países del cono sur; es decir, fenómenos transfronterizos que desembocan en un importante aporte a la diversidad espiritual, ideológica y simbólica latinoamericana a comienzos del siglo XX.

La sección 2 se titula "La cuestión campesina e indígena en las relaciones entre Bolivia y Chile" y agrupa los artículos "Aymaras sin fronteras, prácticas paradiplomáticas al servicio de la (re)territorilazación identitaria”, por el Dr. Gilberto Aranda y la Dra. Mary Gely; "Cariquimas, Islugas y Llicas: La frontera chileno-boliviana de Tarapacá y las disputas interétnicas por los recursos productivos de altura, 1883-1931", por Luis Castro; y "Ya no somos las campesinas del 52. Clase, etnia y género en la Federación Departamental de Mujeres Campesinas indígenas originarias de La Paz Bartolina Sisa, 1980-2010", por Nadia Padilla. Esta segunda sección devela al indígena como actor paradiplomático, sobre todo en la zona fronteriza entre Bolivia y Chile, conjugándose con nociones como identidad, género y subalternidad. Cada artículo demuestra la lucha por (re)configurarse, por comprender su existencia y actuar como algo más allá a una nacionalidad. La clase, la etnia y el género concurren a develar redes y actores subvalorados como agentes de importancia en relaciones paradiplomáticas entre Bolivia y Chile. En suma, este apartado 
rescata una arista silenciada por la historiografía nacional, pero que cada vez toma más fuerza en las denominadas historias regionales y locales, añadiendo a este debate el componente transfronterizo.

La sección 3, titulada "La cuestión regional en las relaciones entre Bolivia y Chile", agrupa los artículos "Bolivia y Chile: Los caminos diplomáticos que se bifurcan y el camino equidistante de la paradiplomacia", por el doctor y Premio Nacional de Historia 2014, Sergio González; "Desde las imágenes nacionales hasta el reconocimiento del legado andino. Dos perspectivas de entender las relaciones internacionales entre Chile y Bolivia", por José Antonio González; "La acción internacional de Jorge Soria Quiroga, Alcalde de la municipalidad de Iquique. Paradiplomacia e imaginación geográfica 1965-2015”, por Rigoberto Sánchez; "Disposiciones en la zona fronteriza de Tarapacá y en los migrantes bolivianos: Una interpretación foucaultiana de las dinámicas transfronterizas durante el ciclo del salitre (1880-1930)", por Luis Iturra; "Segregación discursiva en Tarapacá: el caso de los inmigrantes bolivianos en la pampa salitrera (1900-1910)", por Pamela Fernández; y "Abriendo fronteras, creando mercados: La acción de la Asociación Salitrera de Propaganda como institución paradiplomática de carácter industria en Sudamérica (1894-1909)", por Diego Lizama. La sección tercera configura un fructífero diálogo entre los artículos, guiados por la búsqueda de revelar mecanismos de integración (cultural, económica, social y étnica, entre otras), geolocalizada en la región de Tarapacá y en donde el intercambio (en diversas variantes) potencia la zona como una plataforma de paradiplomacia, de integración, de sucesos históricos difíciles de encontrar en otra zona del país.

Por último, la sección 4, "Estados nacionales e historia compartida", está compuesta por los artículos "Política internacional en la era del pachakuti: el caso del pensamiento indiano en la Bolivia de Evo Morales", por el Dr. Cristian Garay; "La construcción de los Estados de Chile y Bolivia a principios del siglo XIX y el peso de la historia", por Loreto Correa; "La cuestión de la soberanía en la reivindicación marítima boliviana: dos propuestas y una lectura alternativa", por el Dr. Cristian Ovando; "Educación superior e integración Bolivia y Chile", por Orietta Ojeda; "El Puerto de Cobija y la migración peonal. Transformaciones a inicios de la república", por Javiera Letelier Cosmelli y Victoria Castro Rojas; y, por último, "Bolivia y los 'Asuntos del Pacifico'. La mirada de dos diarios españoles, 1903-1912”, por el Dr. Cristián Garay en segunda instancia. Esta sección nos sumerge en otro tipo de discusión, donde lo político es el hilo conductor; la implementación de políticas internas pensadas en agentes extranjeros, la integración internacional por medio de la academia y la visión española en decisiones políticas bolivianas. Esta sección nos llama a aprender un poco más de la historia boliviana y chilena; sus relaciones cercanas, sus encuentros y desencuentros. 
Con todo, esta es una obra de trabajo colectivo o al menos inspirado por los mismos motivos: contribuir a una comprensión más integral de las relaciones bilaterales entre Bolivia y Chile que, hasta ahora, se asocian solo a las relaciones interestatales. Como señalan sus editores, se ha considerado necesario realizar una lectura de segundo orden; es decir, dejar de lado los relatos cuyos argumentos ya clásicos sobre las relaciones entre Bolivia y Chile están basados fundamentalmente en el litigio diplomático.

Por lo tanto, es necesario hacer otra lectura de esos cien años desde que se firmó el Tratado de Paz y Amistad entre Bolivia y Chile; es preciso construir nuevos relatos basados en una historiografía que rescate otros sujetos y otras escalas de análisis. Se considera fundamental en esta tarea el aporte de la microhistoria, de la fenomenología de las relaciones internacionales, la crítica epistemológica al nacionalismo metodológico, la nueva geografía cultural, etc. 